\title{
Acoustic Epistemology in Education
}

\author{
MILENA DROUMEVA \\ Simon Fraser University
}

\begin{abstract}
Epistemology - the question of what knowledge is and how it is acquired - is naturally an important one in the discursive domain of education. Yet, educational notions of epistemology still rely almost exclusively on text in order to define, store and convey knowledge. Formal curriculum is also primarily encoded in and understood through text. Despite the critical interventions of theorists such as Walter Ong and Marshal McLuban who expose the visual and literary bias of our culture, as well as educators such as Barry Truax and R.M. Schafer who have advocated for the phenomenological benefits of listening and orality, education is a long way from shifting its epistemological paradigm from one that is text-centric to one that involves the body and the senses as foundational elements to knowledge construction, teaching practice and curriculum. This paper focuses particularly on orality and acoustic dimensions of communication, and proposes implications for how they might be important to educational practice and institutional conceptions of knowledge.
\end{abstract}

\section{Introduction}

Epistemology - the question of what knowledge is and how it is acquired - is naturally an important one in the discursive domain of education. Yet, educational notions of epistemology still rely almost exclusively on text in order to define, store and convey knowledge. Formal curriculum is also primarily encoded in and understood through text. Despite the critical interventions of theorists such as Walter Ong (1982) and Marshal McLuhan (1962) who expose the visual and literary bias of our culture, as well as educators such as Barry Truax (2001) and R.M. Schafer (1973) who have advocated for the phenomenological benefits of listening and orality, education is a long way from shifting its epistemological paradigm from one that is text-centric to one that involves the body and the senses as foundational elements to knowledge construction, teaching practice and curriculum. This paper focuses particularly on orality and acoustic dimensions of communication, and proposes implications for how they might be important to educational practice and institutional conceptions of knowledge.

I will argue that a revisiting and re-prioritizing of orality as a fundamentally different paradigm of epistemology will benefit education in at least two ways - one being the enriching of educational theory and educative practice by opening up traditional notions of epistemology to conceptually develop a theory of acoustic epistemology; and secondly, the expanding of the idea of orality to include and embrace the concept of aurality - the experience of an acoustic reality beyond speech - and elucidate its connections to an educational context. What the paper attempts to do is first, contextualize these perspectives within educational discourses of epistemology, and then build the notion of acoustic epistemology using a constructivist approach from the theoretical explorations of Walter Ong (1982), David Olson (1977) and R.M. Schafer (1977), as well as the ethnographic work of Steven Feld (1993), Rowland Atkinson (2007) and Tom Rice (2002). This is a first step in a much

(C) Copyright 2006. The author, Milena Droumeva, assigns to the SFU Educational Review the right of first publication and educational and non-profit institutions a non-exclusive license to use this document for personal use and in courses of instruction provided that the article is used in full and this copyright statement is reproduced. Any other usage is probibited without the express permission of the author. 
larger process of opening a space in educational discourse for notions of epistemology that encompass modalities beyond literacy and text. Thus its contributions will be preliminary and modest. In light of both ecological education, which uses an experiential phenomenological stance towards knowledge acquisition (Garrett et al. 2003), as well as media-based education, which emphasizes the influence of different modalities to the nature and process of learning (Goodman, 2003), the fundamental question is the same - do our different senses - modalities of perception - inherently foster different ways of learning and unique notions of what knowledge is? Given the sociocultural histories of the role these modalities have played in society, it is not only fruitful but necessary to explore how they each might enrich the educational experiences in classrooms today, and how they can be understood better and incorporated into teaching practice.

In order to address this subject, it is necessary to first situate it within a larger educational conversation involving alternative epistemologies, as well as a pedagogy that rests on paradigms of embodied philosophy, environmental awareness, imagination and play (Egan, 2007). With the philosophical advent of phenomenology represented through the writings of Husserl, Merleau-Ponty, Varela and others, the locus of knowledge has shifted from an analytical hermeneutic to an experiential one. As Davis and Sumara (2006) argue in their work on hermeneutics and education, the notion of the embodied mind emerged historically when "perception was reinterpreted not as the point of disjuncture but the site of unification of agent and context" (p.71) and that is precisely where knowledge exists. Another relevant discourse is that of Dewey's pragmatism aligned with historical and scientific movements involving Darwin, Rousseau and Vico, and predicated on the notion that "learning is all about an endless tinkering that's made necessary by the fact that learner and context are dynamic and co-implicated." (Davis \& Sumara, 2006, p.71). Paired with de Saussure's theory of language and semiotics, Derrida's deconstructivist critique and emphasizing the interdependence and co-constitution of language, meaning and knowing, this set of paradigms forms the appropriate discursive space for bringing acoustic epistemology into educational theory. As I will argue in this paper one of the main characteristics of an "aural" basis to educational practice is a focus on situatedness, contextual and relational co-constitution of meaning. Yet, to make one final distinction, while the question of orality could be discussed and understood from the perspective of phenomenological hermeneutics as a philosophy underlying particular educational practices, I limit the current exploration to only establishing a conceptual framework of acoustic epistemology and its main features and affordances. Such a framework aims to bring together orality and aurality in a manner that describes their core characteristics in relation to epistemology. This I see as a necessary first step towards a more philosophical grounding of acoustic epistemology as a phenomenological paradigm in education. Thus, for the purposes of the current work, the distinction made between oral/aural and textual bases for conceptualizing and building knowledge will be made from the standpoint of a modality distinction, and not based upon hermeneutic implications.

\section{Language and Orality}

In order to begin exploring the idea of orality and its place within educational notions of epistemology, we have to establish the obvious - the opposite, first - how literacy has shaped education and the construction of what knowledge is. As David Olson (1977) argues, "models of comprehension [in education].... were models that assumed a 'textual or 'sentence' meanings uniquely available to literates, rather than the intended meanings attended to by non-literates ... whether they are pre-literate children or adults living in a non-literate culture"(p.258). As Olson further points out, literacy brings specific underlying principles of meaning, truth and function, radically different from the ways in which they play out in oral traditions. Literacy, he argues, is essentially a move towards more explicitness in language resulting (ideally) in universally shared understanding, where text stands on its own and "meaning is in the text" - comprehension then, becomes a "problem of the learner" not one of the 
writer (p.277). In oral situations, meaning is constructed through the shared effort of speaker and listener; intention, as well as interpretation, is a joint responsibility. Truth encoded in text is, in the Platonic tradition, conceived to be immutable and fixed. Since then, text has given birth to discourse. Oral communication, however, is still in the domain of the present, still conceived and articulated in a quest for shared meaning. Function in written language is predicated on logic and ideation, as opposed to speaking which favours interpersonal and contextual knowledge. As Paul Ricoeur (1973) reiterates, writing makes language a discourse, it posits "the objective meaning of the text as distinct from the subjective intention of the author." (p.93). Further he states of the problem with interpretation of text:

The concept of 'hermeneutic circle' ... does not proceed so much from an inter-subjective relation linking the subjectivity of the author and the subjectivity of the reader, as from a connection between two discourses: the discourse of the text and the discourse of the interpretation." (p.93)

So what does this mean to an education that is conceived and practiced within the paradigm of literacy and through text? Through the centuries, knowledge has become permanently encoded, preserved and passed on through writing, and in turn literacy has become the underlying locus of education. (Havelock 1982; Ong 1982). Dewey (1944) suggests that this is necessitated by the widening gap between amounts of knowledge that have to be imparted to those being educated in order to reproduce social order in its full complexity. Perhaps unlike Ong (but again, perhaps not), he assumes that an oral culture is less sophisticated, while in "advanced cultures much of what is to be learned has to be] stored in symbols" (p.7). While Dewey recognizes that "not only is social life identical with communication, but all communication (and hence all genuine social life) is educative" (p.12), he does not make a distinction between oral and literate forms of communication and hence - knowledge creation, which to Ong constitute radically different epistemological realities.

In order to develop the idea of orality, Ong (1982) examines and describes cultures of 'primary orality' - societies that operate in ways that are foundationally based in speech and listening, and not in writing and text. This way he elucidates the idea that the mode of communication and primary interaction with one's world is critical to the formation of certain forms of knowledge and particular conceptions of what knowledge is in a society is. As an extension of Ong's argument, this paper suggests that from an educational standpoint, what limits our understanding within the practice of teaching and the experience of learning is not ignoring orality in the quest for understanding literacy, but precisely not understanding orality and not recognizing the unique epistemological relations it offers. Education concerns itself a great deal with language, yet it often fails to recognize that orality is not simply a predecessor of writing and the textual 'structure' of language - it is an independent medium of sensation with its own possibilities for understanding and knowing, and exists alongside literacy. It has been prematurely abandoned as a locus of knowledge in favor of literacy, which is seen as successively newer and thus more 'evolved'. Articulating the significance of orality - and as an extension, of aurality - within an educational conversation then becomes a springboard for a discussion about forms of epistemology that transgress literacy and necessitate inclusion into pedagogical theory. Embodiment, situated cognition and precognitive perception have become buzzwords in both the world of technology and education. However, their theoretical implications for epistemology and learning are yet to be developed. Constructing the notion of acoustic epistemology in particular is one attempt to excavate and rebuild a plane of sense-making and knowledge creation that we already engage in, alongside engaging in text.

\section{Acoustic Epistemology}

To refresh our definition - epistemology is a theory of what knowledge is, and how we acquire it. So acoustic epistemology, it follows, should entail both an aural way of knowing - a knowledge that is 
aural or acoustic, as well as the way in which it may be acquired, which would be through the sense of hearing. But what does it mean to talk about an epistemology independently from text and independently from the analytical, abstract forms of knowledge and communication that literacy fosters? We could start by linking acoustic epistemology to the ways in which learning happens and is defined through sound, including the types of understandings we gain through sound and listening, but more importantly, tracing the ways in which orality and aurality shapes the very nature of knowledge. The way Walter Ong (1982), as well as David Olson (1977) define orality, in contrast to literacy helps us formulate a few important grounding principles of what knowing in an 'aural' way is. First, Ong makes an important distinction regarding orality that departs from the linguistic theory of de Saussure, suggesting that writing is not just a representation of oral speech but a separate form of expression. While the study of phonetics illustrates relationships between utterances and meanings as a system of abstract mapping that forms language, it is not language that we are concerned with here. Indeed, what matters to the idea of acoustic epistemology is not the connection between speaking and language, but the relationship between speaking, existence and knowing, as well as the very activity of speaking and listening and the ensuing ways in which they shape relations between people and environment, between meaning and knowledge.

The concept of acoustic epistemology could be traced in the works of several people from within the disciplines of sociology, ethnomusicology and anthropology. Notably, Steven Feld (1993) was the first to articulate the term acoustemology or acoustic epistemology based on his longitudinal fieldwork in the Botsavi forest in Papua New Guinea with the Kaluli people. When Feld studied the acoustic environment of Papua New Guinea he realized that local inhabitants used and performed sounds to refer to locations, directions, natural processes, time and community events. This led him to define that community as a primarily aural one. Some of the examples he found that linked speech and environmental sound with the culture of Kaluli people reside in language, or what he calls "phonetic synaesthesia". In addition to many onomatopoeia words, the notion of 'lift-up-over-sounding' that is central to Kaluli culture could be related to the western idea of 'harmony', however in Botsavi, it is "both a grand metaphor for natural sonic relations...as well as for social relations" "This notion describes the soundscape of the rainforest with its layers of aural density, tonality and timbres, "always in tune but out of phase." It is interesting to note that unlike the Western concept of 'harmony' which implies a unison of voices or sounds coming into 'One', the Kaluli concept of 'lift-up-over-sounding' recognize the counterpoint of natural soundscapes, the interplay of difference, which complements one another, instead of converging (conforming) into one. Both language expressions and musical expressions prevalent in Kaluli culture represent and embody the 'lift-up-over-sounding' concept. Feld describes in detail how expressions about time and places in the forest, as well as directions and geographic orientations are often derived from sounds of nature, or reference sonic phenomena in the forest. In addition, folk songs, especially burial ceremony singing styles - Feld's ethnomusicology dissertation focus - are directly imitative of various bird songs and song styles. Local reality, language and soundscape are thus tightly interconnected in Botsavi's acoustemology.

\section{Sounding Places}

In anthropological and ethnographic works on sound, acoustemologies are almost always primarily associated with the experience and sense of 'place'. The significance of sound to time and place is echoed in Thoreau's descriptions of his soundscape in Walden (1854) - the way certain bird calls marked different portions of the day with amazing precision, as well as the train whistle going on far away into the mountain in the evening, reminding him of human activities and situating him in a community of sharedness. Thoreau (1854) describes these sounds in meticulous detail, revealing to the

\footnotetext{
${ }^{1}$ The source of the quotations from Feld is not paginated.
} 
reader how prominent and defining these sonic characteristics were of his environment, and how influential they were in forming his experience of that environment. Similarly, Schafer's work with the World Soundscape Project (WSP) many years later reveals a similar connection between the aural world and notions of place and time, as demonstrated through numerous interviews with people about their local soundscapes. In Canadian Soundscapes, as well as Five Villages -the results of several years' worth of ethnographic work around the world- Schafer's (1977) team describes the significance of different 'soundmarks' to local soundscapes, as well as the presence of various 'keynote' sounds, and signals and their importance to local residents. According to Schafer, soundmarks, in particular, termed after visual landmarks, are sounds that listeners associate strongly with their acoustic community these are anything from factory steam whistles, to water streams, church bells and typical bird songs. When Thoreau speaks of sounds in his dwelling in Walden, he describes them as elements that characterize in a really fundamental way his existence there, his sense of time, place and experience of community. Time and place, then, are often inseparable experienced through sound. Sounds exist both symbolically and physically in a temporal and geographic domain at once.

In his ethnographic work, Feld (1993) echoes the same conclusions by describing how sounds become a "path" in Kaluli culture - series of "place-names" that link the cartography of the rainforest with its present and past inhabitants, thus making acoustic knowing a "special kind of knowing" one's geography, making "sonic sensibility ... basic to experiential truth in the Botsavi forests." Similarly, in an acoustemology of hospital sound, Tom Rice (2002) points out how the significance of various equipment beeps as well as acoustic 'hospital' sounds - both human and mechanic - define and situate its inhabitants within a physical and metaphoric place. Rice notes that "sound, combined with an awareness of sonic presence, is posited as a powerful force in shaping how people interpret their experiences" (p.7). It is through sound that the world in the hospital comes out of "nothingness into existence" (Rice). In an urban study on noise and ecology, Rowland Atkinson (2007) articulates a similar position on the role of soundscape to the experience of place, time, community, noise and ecology in an urban setting, albeit from quite a different standpoint. His suggestion that "the spaces of the city form an ordered as well as a temporally defined ecology of noise and relative silence" (p.4) is tested out in a survey study with tinnitus sufferers, and analyzed from a Foucauldian perspective. The purpose of the study is to elucidate the relationship between noise and geography as it influences the lives of tinnitus sufferers who are forced to actively avoid noisy areas in the city. While noise and silence form mutually exclusive physical and symbolic areas, it is the silence-seekers who are subjugated and burdened with the onus of active avoidance, while noise-producers are endowed with symbolic power and control. According to Atkinson, this pattern of noise avoidance positions urban experience as an "ordered ecology of spaces with acoustic qualities that affect patterns of socialization" (p.8). Again, the temporal and geographic qualities of the soundscape are always in the process of active constitution of experience, reality, human activity and communication.

\section{Sounding Time}

\footnotetext{
"All sensation takes place in time, but sound has a special relationship to time...Sound exists only when it is going out of existence. It is not only perishable but evanescent, and is sensed as evanescent... There is no way to stop sound and have sound. If I stop the movement of sound, I have nothing - only silence, no sound at all." (Ong, 1982 p.32)
}

The first concept relating to acoustic epistemology to emerge out of Ong's (1982) work is sound's relationship to time. Unlike the written word, sound carries no residue. While writing allows stories, thoughts and ideas to live in text, sound exists only in the possibility of being uttered. In addition to denoting temporal transitions in a day, and creating a sense of community, the relationship of sound to time as articulated by Ong carries epistemological implications. The lack of 'residue' created by sound (in contrast with written text) fosters in primarily oral cultures a conception of knowledge, 
communication and preservation that is fundamentally linked with experience, storytelling and listening.

Memory becomes a central element in the oral world, since "you know what you can recall" (p.33). Ong further articulates two central underlying principles of orality - storytelling and mnemonic expressions. Both of them essentially result from sound's ephemeral qualities. Storytelling, claims Ong, develops characteristics that make it easy for an aural imparting of knowledge: utterances in storytelling are aggregate - qualities and events stagger on top of each other; aural affordances are linear - stories move in sequence; they are redundant - sound's evanescence makes it necessary to repeat and reiterate important points. In terms of referential techniques, oral storytelling is human-centered, (inter)personal and deeply embedded in experience, maintaining a constant link to the local, the familiar, and the associative. In a similar way, Olson categorizes oral utterances as communicative practices that always require private, referential context in order to be understood and interpreted correctly. The nature of meaning in oral exchanges therefore develops to be naturally ambiguous - in contrast to the quest of literacy to be explicit and universal! According to Olson, context and pre-existing knowledge, as well as paralanguage all combine to convey the speaker's intention. For Olson, aural meaning is also linked to activity - 'to understand why the baby is crying you have to see what the baby is doing" (p.261). This brings up the next point Olson makes, which is that oral exchange is essentially dialogical. Unlike text, which leaves no opportunity for the reader to engage directly with the author, speech, and I'll argue, by extension - the aural experience of soundscape, always creates a dialogue, an open-ended, two-way exchange (Truax, 2001). Central to this dialogical nature of orality is a communication of intention, requesting a reaction.

A more expansive example comes again from the work of Steven Feld, (1993) with the concept of 'lift-up-over-sounding' that represents a reality where ritual song does not simply borrow its tonal, timbral and stylistic patterns from the sounds of nature, but it is in turn performed in concert, in sonic counterpoint, with the natural soundscape of the rainforest, as a perfect embodiment of Schafer's notion of acoustic ecology. Truax's (2001) work on acoustic communication emphasizes understanding sound's role in the contemporary environment on elucidating the functions and practices of listening that influence and are influenced by patterns of communicative exchange. Sound is discussed from the standpoint of being an interactive modality, which is informative and significant; there is always a moment of learning and understanding that occurs during the complex process of listening. Sound also places importance on the role of context to the process of listening, which Truax defines as "the processing of sonic information that is usable and potentially meaningful to the brain" (p.11). This notion emphasizes the listener's ability to extract meaningful information from the content, qualities and structure of the sound precisely by situating this process in their knowledge and familiarity with the context and environment (p.12). This conceptualization of listening-in-context reinforces and is connected to the notion of acoustic epistemology discussed here, demonstrating the unique possibilities aurality offers to the construction of knowledge. With the acoustic communication model, the soundscape can be seen as a multi-faceted point of reference representing the many relationships that sound mediates between environment, society, listeners, culture, public and private domains.

\section{Acoustic Epistemology and Education}

After having detailed and elucidated some underlying qualities of orality, as well as aurality, inasmuch they constitute the notion of acoustic epistemology as a conceptual framework, the next step in this theoretical synthesis would be to articulate their relation and importance to education, as well as possible implementations in curriculum. As this is an ambitious task for this very preliminary attempt to enter acoustic forms of knowledge into the discursive domains of educational epistemology, I will not attempt to offer definitive or even exhaustive answers. Rather, the contribution of this exploration is to open a space for a neoaural approach to knowledge in educational theory and teaching practice by 
providing examples of it in other disciplines and demonstrating that education has, through its historical development, perhaps prematurely abandoned aural forms of learning and knowing by overrelying on literacy and defining the idea of knowledge through text. Tracing the works of Ong, Olson and McLuhan into orality, as well as the acoustemology fieldwork of ethnomusicologists and anthropologists Steven Feld (1993), Tom Rice (2002)and Rowland Atkinson (2007) and R.M. Schafer's (1977) notion of acoustic ecology, along with Barry Truax's (2001) framework of acoustic communication, it is undeniable that we still live in an aural world where much of our sense of place, self and community is constituted through sound. Knowledge is as much of a cultural product of our sensorial experience with the world, as it is a byproduct of literacy. Thus the manner in which this experience is gathered becomes the basis for thought and action, and needs to be theoretically reappropriated into the conceptualization of knowledge.

While Olson (1977), Ong (1982) and others constitute the elements of orality through its nemesis - literacy, and describe essentially a pre-literate or purely oral reality - our current situation is one of post-literacy, or neo-orality (McLuhan, Schafer, Truax). For this reason Ong and Olson's claims need to be superimposed onto the new conditions of communication and education, and re-evaluated from the standpoint of this new aurality. Both Ong and McLuhan, echoed by Schafer, Truax and others in more recent times, proclaim that the technological, 'electric' post-literacy age we currently live in is one of secondary orality - the orality of voice amplification, telephones, portable audio devices. The historical significance of written text to constituting meaning has in recent times become redressed through the images of mass media, cinema and advertising and the aurality of background music, the Internet, and electronic sound signals. Education's failing to recognize the significance of neo-aurality and its relation to knowledge and experience leaves out an important medium of perception and communication from the domain of education, and prevents learners, teachers and curriculum designers from harnessing the potentials of acoustic epistemology through aural forms of knowing.

Ultimately, the outcome of this exploration into acoustic epistemology would lead to both a greater understanding of aurality as a subject taken up in educative practice, as well as to shifting educative practice itself to allow for a cross-fertilization of epistemological modalities, one of which is the aural. As noted in the introduction, a next step towards deepening the rich and understudied notion of acoustic epistemology is theoretically situating it within educational hermeneutics and aligning it with other experiential and ecological learning paradigms, framed by phenomenology, embodied cognition and philosophy of embodiment. This way, aurality would catch up to epistemological shifts that are already underway in institutional and informal education settings. Such a shift could not happen however, before a deep and thorough theoretical understanding of acoustic epistemology has been articulated. This paper offers, hopefully, a beginning and an opening into a theory of aurality for education.

\section{Acknowledgments}

I'd like to acknowledge the generous help of Dr. Ann Chinnery as well as Dr. Suzanne de Castell in giving me ideas and discussing the beginnings of this topic, and the thoughtful feedback from the journal reviewers in making this work better. As well I'd like to recognize the financial support of SSHRC for this and future work in this area.

\section{References}

Atkinson, R. (2007) The Aural Ecology of the City: Sound, noise and exclusion in the city. UTAS: Housing, Community and Research Unit, Paper 5. p. 1-18. 
Bingham, C. (2005). The hermeneutics of educational questioning, Educational Philosophy and Theory, 37, 553-565.

Dall'Alba, Gloria. (Ed.). (2009). Exploring education through phenomenology: Diverse approaches. The University of Queensland, Brisbane: Wiley-Blackwell Publishing.

Davis, B., \& Sumara, D. (2006). Complexity and education: Inquiries into learning, pedagogy and research. Mahwah, New Jersey: Lawrence Erlbaum Associates.

Dewey, J. (1944). Democracy and education. < http://www.ilt.columbia.edu/Publications/dewey.html> Retrieved on Nov 25, 2007.

Egan, K. (2007) Teaching and learning outside the box: An imaginative approach to education. New York, U.S.A.:Teachers College Press.

Garrett, J., Blenkinsop, S., Box, B., \& Madeja, J. (2003). A teaching guide: Teaching outdoor educator judgment through the Case Study method. [Computer Software]. Garrison, NY: OBUSA.

Goodman, S. (2003) Teaching youth media: A critical guide to literacy, video production, and social change. Columbia University, New York: Teacher's College Press.

Feld, S. (1993). From ethnomusicology to echo-muse-ecology: Reading R. Murray Schafer in the Papua New Guinea rainforest. Proceedings of the First Meeting of the World Forum for Acoustic Ecology, Banff, 1993.

Havelock, E. (1982). Preface to Plato. Blackwell, Oxford: Belknap Press.

Howard, P. (2008) Ecology, phenomenology, and culture: Developing a language for sustainability. Diaspora, Indigenous, and Minority Education, 2, 302-310.

McLuhan, M. (1962). The Gutenberg Galaxy: The Making of Typographic Man. University of Toronto Press.

Olson, D. (1977) From utterance to text: the bias of language in speech and writing. Harvard Educational Review, 41, 257-81

Ong, W. J. (1982) Orality and literacy: The technologizing of the word. London; New York: Methuen.

Plato, $(360$ BCE $)$ The Republic. Translated by Bejamin Jowet< http://classics.mit.edu/Plato/republic.html> Accessed on Nov 25, 2007.

Rice, Tom (2002) Soundselves: An Acoustemology of Sound and Self within the Edinburgh Royal Infirmary. Diffusion. London: Sonic Arts Network: 2-7.

Riceour, P. (1973) Creativity in Language: Word, Polysemy, Metaphor. Philosophy Today, 17, 97-111.

Schafer, R. Murray (1977) The tuning of the world, Toronto, Canada: McClelland and Stewart Press.

Schafer, R. Murray (1993) Voices of tyranny: temples of silence, Ontario, Canada: Arcana Editions.

Thoreau, H.D. (1854) Walden, or life in the woods. Boston: Ticknor and Fields.

Truax, Barry (2001) Acoustic communication (2nd ed.). Westport, CT: Ablex Pub.

\section{About the Author}

Milena Droumeva is a PhD candidate in the Faculty of Education at Simon Fraser University. She has degrees in Communication and in Interactive Arts and Technologies. Her current work centres on the notion of acoustic epistemology both within and outside education. 